\title{
PRÁTICAS DOCENTES E RELAÇÕES ÉTNICO-RACIAIS: REFLEXOS DA SOCIEDADE BRASILEIRA
}

Gabriela Valentel

Adriana Santiago Rosa Dantas II

I Université Lumière Lyon 2, Laboratoire Education, Cultures, Politiques (ECP), Lyon, França; gabriela.abuhab.valente@gmail.com

II Universidade Estadual de Campinas (Unicamp), Campinas (SP), Brasil; novadrica@gmail.com

\section{Resumo}

A discriminação racial é uma prática social que tem origens históricas no Brasil. Sua presença é naturalizada no espaço escolar em virtude do racismo estrutural da sociedade brasileira. Este artigo procura responder à seguinte questão: Como os professores agem diante de situações de discriminação racial? A resposta a essa questão inspira-se na sociologia pragmática, a qual deu suporte teórico e metodológico para uma etnografia sociológica, que recolheu narrativas de professores, na forma de entrevistas, sobre as práticas docentes frente às situações reais nas quais a identidade racial é mobilizada. Além de ratificar a dificuldade dos professores em lidar com racismo como um reflexo da sociedade brasileira, os dados revelaram que o investimento na formação docente é mais produtivo quando os docentes possuem boas condições de trabalho.

DISCRIMINAÇÃO RACIAL • RACISMO • COMPORTAMENTO DO PROFESSOR • SOCIOLOGIA

\section{TEACHING PRACTICES AND ETHNIC-RACIAL RELATIONSHIPS: REFLECTIONS OF BRAZILIAN SOCIETY}

\section{Abstract}

Racial discrimination is a social practice that has historical origins in Brazil. Its presence is naturalized in the school space due to the structural racism of Brazilian society. This article seeks to answer the following question: How do teachers act when facing situations of racial discrimination? The answer to this question is inspired by pragmatic sociology, which provided theoretical and methodological support for a sociological ethnography, collecting narratives from teachers in the form of interviews on teaching practices in the face of real situations in which racial identity is mobilized. In addition to confirming the difficulty of teachers to deal with racism as a reflection of Brazilian society, the data revealed that investment in teacher training is more productive when teachers have good working conditions. 


\section{PRÁCTICAS DOCENTES Y RELACIONES ÉTNICO-RACIALES: REFLEXIONES DE LA SOCIEDAD BRASILEÑA}

\section{Resumen}

La discriminación racial es una práctica social que tiene orígenes históricos en Brasil. Su presencia se naturaliza en el espacio escolar debido al racismo estructural de la sociedad brasileña. Este artículo busca responder a la siguiente pregunta: ¿Cómo actúan los profesores en situaciones de discriminación racial? La respuesta a esta pregunta está inspirada en la sociología pragmática, la cual dio apoyo teórico y metodológico para una etnografía sociológica, recopilando narrativas de los profesores, en forma de entrevistas, sobre las prácticas docentes frente a situaciones reales en las que se moviliza la identidad racial. Además de ratificar la dificultad de los profesores para hacer frente al racismo como reflejo de la sociedad brasileña, los datos revelaron que la inversión en educación docente es más productiva cuando los maestros poseen buenas condiciones de trabajo.

DISCRIMINACIÓN RACIAL • RACISMO • CONDUCTA DEL PROFESOR • SOCIOLOGÍA

\section{PRATIQUES D’ENSEIGNEMENT ET DISCRIMINATION RACIALE : REFLETS DE LA SOCIÉTÉ BRÉSILIENNE}

\section{Résumé}

La discrimination raciale est une pratique sociale qui, au Brésil, a des origines historiques. Sa présence est naturalisée dans l'espace scolaire en raison du racisme systémique de la société brésilienne. Cet article vise à répondre à la question suivante : Comment les enseignants agissent-ils face aux situations de discrimination raciale ? La réponse à cette question s'inspire de la sociologie pragmatique qui apporte un soutien théorique et méthodologique à une ethnographie sociologique. Des récits d'enseignants ont été recueillis lors d'entretiens concernant leurs pratiques pédagogiques face aux situations réelles dans lesquelles l'identité raciale est mobilisée. Tout en confirmant la difficulté que les enseignants ont à faire face à un racisme qui est le reflet de la société brésilienne, les données ont révélé que l'investissement dans la formation des enseignants est plus productif lorsque ceux-ci disposent de bonnes conditions de travail.

DISCRIMINATION RACIALE • RACISME • COMPORTEMENT DE L'ENSEIGNANT • SOCIOLOGIE 


\section{Contexto e questões ${ }^{1}$}

A prática docente e as relações étnico-raciais no espaço escolar são uma temática recente nos estudos da área da educação. Conforme o levantamento de Coelho (2018), que analisou o estado da arte de estudos sobre a formação docente e relações étnico-raciais, o assunto começa a tomar fôlego a partir do ano de 2006. Naquele momento, começam a aparecer alguns artigos e, ao longo dos anos, crescem gradualmente os trabalhos de pesquisa, havendo um ápice no ano de 2013 em razão dos dez anos da promulgação da Lei n. 10.639/2003, conforme deduz a autora. Essa constatação sugere a importância da discussão no campo educacional das relações étnico-raciais, pois remete a um reflexo da sociedade brasileira, a qual tem ocultado o debate racial em diversas áreas. Alguns trabalhos exemplificam a emergência recente da questão somente no novo milênio, enquanto sua gênese está no período colonial e escravista, constituindo-se, portanto, um problema secular com discussão ainda incipiente (Gomes \& Jesus, 2013; Muller, 2018; Coelho, 2018). Uma das recomendações levantadas foi chamar a atenção para a formação docente e os seus sentidos, em virtude da fragilidade da tal formação, tanto inicial quanto continuada, no que tange à temática (Coelho, 2018). Assim, o presente artigo se insere nesse contexto, com o intuito de contribuir para tal discussão ao apresentar dados de uma pesquisa sobre as práticas profissionais cotidianas dos docentes e os desafios das relações étnico-raciais na sala de aula.

Partimos do pressuposto de que o desafio do tema está atrelado à estrutura da própria sociedade brasileira, que tem resistido em discutir o racismo (Telles, 2003; Guimarães, 2009), o que se reflete, assim, no funcionamento da escola. Isso porque a discriminação racial é uma prática social que possui suas origens na história do Brasil escravocrata. Como reflexo dessa estrutura social, a presença da discriminação racial no espaço escolar se dá de forma insidiosa e, muitas vezes, naturalizada e/ou invisibilizada. Contudo, a educação nacional de uma sociedade democrática deveria se preocupar com a educação antirracista, sobretudo em um contexto de desigualdade social profundamente relacionada com o racismo estrutural ${ }^{2}$ da sociedade brasileira, apontada por Hasenbalg (2005) no final do século XX. As análises desse autor relataram que a discriminação tem uma funcionalidade na estrutura da sociedade brasileira, pois, na competição social, os negros estão em desvantagem na mobilidade social em relação aos brancos, e a educação tem um papel crucial nesse quadro (Hasenbalg, 2005; Hasenbalg \& Silva, 1999). Estudos recentes sobre as desigualdades nos últimos cinquenta anos têm demonstrado que a questão racial ainda é um desafio persistente que diferencia o acesso aos melhores postos de trabalho e à educação no novo milênio, o que sinaliza que o racismo ainda está longe de ser superado (Lima \& Prates, 2015; Menezes \& Kirschbaum, 2015).

Apesar dessa disparidade racial na sociedade, a discussão sobre racismo causa relutância no Brasil. Para compreender esse fenômeno nacional é possível se referir ao trabalho de Nogueira (2006), que fez uma diferenciação da situação racial entre os Estados Unidos e o Brasil. Ele propõe que há um preconceito racial de origem que caracterizaria, por exemplo, o norte-americano, e o preconceito racial de marca, o qual se insere no contexto brasileiro. Grosso modo, o primeiro refere-se à discriminação que um indivíduo sofre por descender de um grupo étnico estigmatizado socialmente, enquanto o segundo acontece por traços físicos individuais, os quais correspondem a um grupo estigmatizado pela aparência. Segundo ele, "onde o preconceito é de marca, a ideologia é, ao mesmo tempo, assimilacionista e miscigenacionista; onde é de origem, ela é segregacionista e racista" (Nogueira, 2006, p. 297). O autor elenca consequências do preconceito racial de marca como "consciência intermitente da discriminação", quando ela é contínua no preconceito racial de origem. Assim, o racismo no Brasil se dá de forma descontinuada e velada, por não se ter uma consciência clara da discriminação.

\footnotetext{
1 Uma versão abreviada deste texto foi publicada nos Anais do $45^{\circ}$ Encontro Nacional de Estudos Rurais e Urbanos em 2018 , sob o título "Direito à educação e racismo no espaço escolar: a ação docente". Os dados e análises apresentados neste texto foram recolhidos durante pesquisas financiadas pela Fapesp - processos n. 2015/22243-8 e 2019/09919-3.

2 Conforme Jones (1973) e Almeida (2018).
} 
O fator cultural que teve grande impacto no ocultamento do racismo no Brasil foi a perpetuação da crença da democracia racial. Ela foi elaborada com base nos estudos de Freyre, cuja obra clássica Casa-grande \& senzala (Freyre, 2004/1933) teve grande receptividade em solo brasileiro e internacional. Como demonstrou Hasenbalg (2005), a democracia racial foi um mito creditado ao povo brasileiro, que nada mais é do que um instrumento de legitimação das desigualdades sociais. Uma de suas consequências tem sido a dificuldade do debate público do racismo na sociedade brasileira ao longo do tempo. A miscigenação e o projeto de embranquecimento não permitiram que os negros brasileiros construíssem uma comunidade coesa em defesa dos seus direitos, como ocorre em países em que a segregação é evidente. Um dos resultados é o obstáculo de identificar as práticas racistas, pois elas estão camulladas (Guimarães, 2009).

O papel da educação nesse quadro relaciona-se à escola como lócus institucional de propagação ou não do racismo. Para fomentar o debate de maneira didática, Almeida (2018) divide o racismo em três concepções: a individualista, a institucional e a estrutural. A primeira remete a uma discriminação direta produzida por um indivíduo, considerada um mal moral no corpo social. Essa concepção individualista é frágil, pois não historiciza o fenômeno e seus efeitos reais na sociedade. A concepção institucional, a qual é um avanço para o autor em comparação à concepção individualista, compreende o racismo no funcionamento das instituições, o qual pode conferir privilégios ou desvantagens a partir da raça; em outras palavras, o racismo é tratado pela ótica do poder e da dominação. Por fim, a concepção estrutural avança na formulação do racismo quando o compreende como uma materialização de uma estrutura social racista. Na concepção do autor: "em uma sociedade em que o racismo está presente na vida cotidiana, as instituições que não tratarem de maneira ativa e como um problema a desigualdade racial irão facilmente reproduzir as práticas racistas já tidas como "normais" em toda a sociedade" (Almeida, 2018, p. 37).

Assume-se neste artigo a existência de mecanismos estruturais que operam na mobilidade social de diferentes grupos, conferindo, por exemplo, desvantagens a negros. Nesse sentido, a escola como instituição social pode propagá-lo ou enfrentá-lo. Em outras palavras, o racismo, em contraponto ao direito à educação, liga pessoas negras a estereótipos e a representações negativas que se autorrealizam e limitam o seu campo de ação.

As escolas são instituições de socialização que participam do processo de construção da identidade individual a partir do processo de socialização (Darmon, 2016), inseridas na cultura de uma sociedade. Por isso, refletem tal cultura e sua historicidade. $\mathrm{O}$ ensino formal brasileiro nasceu em um contexto escravocrata para atender às necessidades das elites brancas em educar seus herdeiros, tendo na Igreja Católica uma das principais instituições que levaram essa tarefa a cabo (Cunha, 2017; Haidar, 2008). Naquele contexto, foi se formando uma escola na qual os negros estavam, majoritariamente, excluídos, tanto do espaço físico quanto dos conteúdos curriculares.

A questão racial foi sendo propagada desde então pelo paradigma de ausência, conforme definiu Nascimento (2016), que se refere à não presença do protagonismo dos negros no currículo escolar, o qual não permite compreender o papel das conquistas sociais desse grupo. Tal paradigma se solidificou, pois, para o autor, havia o interesse dos brancos em associar os negros a estereótipos de marginalidade social.

$\mathrm{Na}$ atualidade, há uma somatória de fatores recebidos como herança desse passado escravocrata, conforme alerta Munanga (2005). Dentre eles, destaca-se o conteúdo eurocêntrico dos materiais didáticos, que refletem o negro de maneira discriminatória, como ratificam as pesquisas de Silva (2005) e Muller (2018). Além disso, há as relações preconceituosas entre os próprios alunos, com as quais os professores não se sentem preparados para lidar. Tal dinâmica no espaço escolar incide de forma cruel sobre os alunos negros, resultando em maior índice de evasão e repetência, se comparado aos estudantes brancos. Munanga (2005) ainda alerta para o preconceito que está arraigado no professor, produto do racismo estrutural no qual o docente está inserido, o qual necessita de um processo ativo 
de desconstrução para superação do racismo. Ao longo desses últimos séculos, o movimento negro organizado foi um ator político educador, conforme explica Gomes (2017). Dentre as diversas conquistas, a que confronta a problemática da ausência do protagonismo negro no espaço escolar é a Lei n. 10.639/2003, que normatiza a inclusão da história e cultura afro-brasileiras no currículo básico de ensino como enfretamento dessa problemática.

Este artigo apresenta resultados de uma pesquisa que teve como objetivo compreender como as questões étnico-raciais se apresentavam na prática docente. $\mathrm{O}$ suporte teórico foi a sociologia pragmática e, como metodologia, apoiando-se na etnografia sociológica (Beaud \& Weber, 2014), utilizou-se a observação de campo e entrevistas com professores. Essas duas ferramentas metodológicas permitiram a recolha de situações vividas e descritas pelos docentes. Assim, as unidades de análise são constituídas por situações reais que implicam as relações étnico-raciais no espaço escolar. Sua análise busca contribuir para o debate da naturalização da prática racista quando não se descontrói o racismo institucional e estrutural na prática docente, assim como demonstrar práticas antirracistas de profissionais impulsionadas por uma atividade profissional reflexiva e por condições de trabalho favoráveis. O contexto para análise foi a assunção de que a discriminação racial é um assunto árduo de ser discutido, como será visto mais adiante pelos dizeres de alguns professores, fato esse que espelha a maneira como a sociedade brasileira trata o assunto.

As situações que serão apresentadas no decorrer deste trabalho atestam o revés por parte dos professores em reconhecer o racismo ou convencer seus pares e alunos de que determinada prática é discriminatória. Revelam ainda a desvalorização das práticas da cultura dominada, especificamente no que se refere à religião de matriz africana, pois é difícil reconhecer que o campo religioso cristão contribuiu e ainda contribui para a distinção e depreciação dos negros no Brasil.

Notou-se na pesquisa a falta de compreensão do racismo por parte de negros ou mesmo a falta de autorreconhecimento da própria negritude, faltas essas que constituem um obstáculo para a superação do racismo entre os próprios alunos negros, que muitas vezes não se consideram como tais, por causa da miscigenação. Isso acarreta a produção de bullying por aqueles de pele mais clara contra aquele que tem o fenótipo negro, como a pele mais escura ou o cabelo crespo, por exemplo. De forma geral, o preconceito racial brasileiro de marca tem se caracterizado por deixar o racismo em um campo nebuloso, de difícil identificação, tanto por parte do agressor quanto daqueles que sofrem o racismo, dificultando suas desconstruções. Isso afeta os professores, que necessitam (re)conhecer essa faceta do racismo na sociedade brasileira para se posicionar em sua prática docente. Algumas questóes foram levantadas neste trabalho: Como os professores agem frente a situações de discriminação racial? Como os docentes têm entendido a Lei n. 10.638/2003? Será que ela oferece a garantia de uma educação cidadã?

Os elementos metodológicos para compreender essas questões que nos permitiram discutir as práticas docentes e as relações étnicos-raciais, bem como os detalhes do corpus de pesquisa, serão apresentados na primeira parte deste artigo; em seguida, traremos a análise das situações, divididas em três grupos, a saber, racismo estrutural, Lei n. 10.638/2003 e racismo religioso. Por fim, teceremos algumas considerações finais.

\section{Aspectos metodológicos}

Com o objetivo de realizar uma análise do currículo real (Gimeno-Sacristán, 2000), ou seja, da prática real dos professores diante de determinadas situações escolares, inspiramo-nos na sociologia pragmática (Nachi, 2012) e em uma etnografia sociológica (Beaud \& Weber, 2014). As narrativas de professores foram recolhidas na forma de entrevistas.

A entrevista foi escolhida como técnica de coleta de dados por ser uma maneira de obter informações sobre as percepções, os julgamentos de valores, as representações dos professores 
(Van der Maren, 1995) com relação à sua própria prática docente. Trata-se de entrevistas etnográficas, ou seja, entrevistas que não são isoladas de uma conjuntura de pesquisa e nem de um contexto social e cultural, nacional e local (Beaud \& Weber, 2014). Com base nelas, buscou-se compreender as formas de ser, agir, pensar e sentir desses sujeitos por meio do relato de experiências e da reflexão sobre algumas situações vividas pelos docentes, uma vez que essas disposições pessoais orientam as práticas docentes em sala de aula. O roteiro semiestruturado de entrevista estimulou professores a emitirem sua compreensão sobre algumas de suas ações em situação, bem como lhes deu a oportunidade de refletir sobre suas ações nessas ocasiões. Essa técnica de pesquisa foi estabelecida pela coordenação da pesquisa internacional "Religião, discriminação e racismo no espaço escolar" (ReDISCO), da qual este estudo faz parte. ${ }^{3}$

Foram entrevistados 18 professores de ensino fundamental II de sete escolas públicas diferentes da cidade de São Paulo e de sua região metropolitana no primeiro semestre de $2016 .{ }^{4}$ O contato com os primeiros professores se deu por conta de observações de campo anteriormente ocorridas nas escolas em que os docentes atuavam. Percebendo-se a necessidade de abarcar a diversidade do professorado paulista relacionada ao local geográfico, foi utilizado o método "bola de neve”, em que os primeiros informantes indicam outros para compor uma amostra não probabilística. Assim, realizamos entrevistas com professores, diretores e coordenadores de escolas paulistas até a chegada do "ponto de saturação", quando as informações começaram a se repetir (Albuquerque, 2009).

Com o objetivo de analisar as práticas docentes em situações envolvendo a questão das relações étnico-raciais, as situações descritas pelos entrevistados foram utilizadas como unidades de análise, uma vez que elas são singulares e envolvem as dimensões subjetivas dos atores (Boltanski \& Thévenot, 1991). As situações permitem levar em consideração as significações que os atores atribuem à ação e as exigências de ações específicas, dificilmente repetidas. Nesse sentido, o ator é desafiado, em cada situação, a descobrir a sua potencialidade do agir, tateando o seu estilo profissional, construindo sua identidade e (re)ativando suas disposições. Ademais, a ação em situação inclui preocupações pessoais e profissionais que estão relacionadas com as relações sociais do coletivo do trabalho (Amigues, 2003).

Assim, a análise desse material permitiu contabilizar 78 situações envolvendo a questão religiosa, a discriminação e o racismo. Apenas 11 docentes reportaram 13 situações que os próprios entrevistados classificavam como situações envolvendo relações étnico-raciais. ${ }^{5}$ Por meio do cruzamento entre o método indutivo (Blais \& Martineau, 2006) e o método dedutivo (Van der Maren, 1995), criaram-se categorias de análise (estratégias de ação, objetivos das estratégias, recursos para ação, lógicas de ação) e as situações foram codificadas.

As situações aqui apresentadas são representativas da pluralidade de comportamentos e de visões de mundo que seriam compartilhadas pelo grupo professoral, revelando o gênero profissional docente (Clot, 2008), o processo de socialização docente e, ao mesmo tempo, apontando indícios para as origens dos recursos e disposições dos docentes. Antes de passar para a apresentação de alguns resultados dessas análises, traçaremos o perfil dos professores entrevistados.

3 Pesquisa coordenada pela professora Françoise Lantheaume, da Université Lumière Lyon 2, na França. O estudo aborda as temáticas com base no trabalho real dos professores em uma perspectiva internacional, envolvendo o Brasil (em diferentes regiões), a Suíça e o Canadá, além da própria França.

4 A pesquisa foi aprovada pela Comissão de Ética da Faculdade de Educação da Universidade de São Paulo e respeitou os procedimentos éticos estabelecidos para a pesquisa científica. Todos os nomes próprios utilizados neste estudo são fictícios e garantem o anonimato dos participantes da pesquisa e das escolas.

5 Dentre os relatos coletados, nenhum docente mencionou a questão indígena. Por isso não evocaremos a Lei n. 11.645 de 2008, que decreta a inclusão da história e cultura indígena no currículo escolar. 


\section{Corpus de pesquisa}

Neste item, primeiramente, apresentaremos os 18 professores entrevistados, sem distinção de local de trabalho e, em um segundo momento, traremos características das escolas em que eles trabalham.

A construção do perfil de professores entrevistados foi feita com base em uma análise indutiva do material coletado durante as entrevistas, em que se buscou encontrar elementos comuns compartilhados por esses sujeitos de pesquisa. Dentre os docentes entrevistados, temos dez professoras e oito professores. A maioria feminina não surpreende por se tratar de uma ocupação cujo processo de profissionalização foi acompanhado pela feminização do grupo profissional (Setton, 2012). Apenas dois professores eram negros.

Sete dos 18 professores entrevistados lecionavam a disciplina de História, e seis, a disciplina de Língua Portuguesa/Redação/Gramática. Dentre os sujeitos que não lecionavam essas duas disciplinas, temos uma diretora (formação em Educação Física), um vice-diretor de escola (formação em História), uma coordenadora pedagógica (formação em Geografia), uma professora mediadora (professora especializada em necessidades educacionais especiais) e um professor de Ciências.

Quatorze são os professores que possuem mais de dez anos de experiência na área da educação. Portanto, trata-se de uma população com experiências docentes diversificadas, o que é interessante para esta pesquisa, pois eram professores com diferentes visões do sistema de ensino e da função social da educação. Dentre os docentes, alguns perfis se destacam. Por exemplo, a professora Ana, de História, que ministrava aulas em uma escola em Itaquera, na Zona Leste da cidade de São Paulo, possuía uma grande atuação no Sindicato dos Professores. Ou Carlos Alberto, o vice-diretor de uma escola no Parque São Rafael, que fundou o movimento punk anarquista da Zona Leste em sua juventude.

Duas escolas tiveram maior representatividade nesta pesquisa por conta das observações de campo ali realizadas e, portanto, terão proeminência neste artigo. Seis professores (Sofia, Natália, Sandra, Eduardo e Henrique) atuavam em uma escola, denominada aqui de Escola Padre Manuel da Nóbrega, no município de Santo André, na região metropolitana de São Paulo, e cinco docentes (Gabriel, Marta, Sarah, Ricardo e Patrícia) atuavam na Escola Academia, na Zona Oeste do município de São Paulo. Além desses, tivemos a oportunidade de entrevistar um docente de História (Anderson), que atuava em duas escolas estaduais no município de Ribeirão Pires na região metropolitana de São Paulo, quatro professores que trabalhavam em escolas da Zona Leste de São Paulo (Itaquera - Ana; Sapopemba - César; e Parque São Rafael - André e Carlos Alberto) e duas professoras que davam aulas em outra escola também localizada na cidade de Santo André (Maraíde e Mônica). As docentes dessa última escola foram contundentes quanto ao perfil dos alunos: eram estudantes que moravam na Zona Leste de São Paulo e que tinham condições financeiras para sustentar uma estratégia de escolarização que lhes permitia buscar o que acreditavam que seria um ensino de melhor qualidade, procurando a escola na cidade vizinha.

A Escola Academia possuía um regime diferenciado de organização institucional, permitindo que os professores tivessem cerca de $40 \%$ de sua carga horária dedicada para a preparação das aulas e reuniões com os colegas ou com os alunos. Além disso, essa escola oferecia projetos transversais para discutir temas como a prevenção de drogas, a intolerância religiosa e a discriminação racial. Este último, o Projeto Negritude, interessa-nos em especial, principalmente pela sua proposta antirracista, o que será retomado no item "Empoderamento do aluno negro".

\section{As práticas docentes em situações envolvendo a questão racial}

Nesta segunda parte do artigo, apresentaremos algumas concepções e práticas docentes dos professores entrevistados com base em três eixos categóricos. O primeiro deles é composto por falas dos docentes que revelam um determinado entendimento sobre as relações étnico-raciais no espaço escolar e na sociedade brasileira. No segundo, coletamos algumas situações que envolviam a questão da implementação da 
Lei n. 10.639/2003. Por fim, apresentaremos outras situações escolares envolvendo a questão racial junto com as práticas docentes que os acompanharam.

\section{"A sociedade do fingir": dificuldades de reconhecimento do racismo}

A dificuldade de reconhecimento de casos de racismo pode ser representada pela fala de três professores que, paradoxalmente, se utilizaram de situações de discriminação racial para justificar a sua ausência. Dito de outro modo, uma situação de discriminação racial foi interpretada como algo pontual ou apenas brincadeiras entre os alunos:

Olha que mesmo aqui, na escola, o racismo aqui da escola que à vezes "o seu preto, o seu cabelo duro, cabelo pixaim" ainda não é uma questão de racismo dentro da nossa escola. Porque aqui, aqui eu chamo até de "brincadeira de mau gosto", porque depois eles ficam brincando. Eu, no social mesmo, nunca presenciei. (Natália)

É ainda mais preocupante quando revelamos o papel de Natália na escola. Enquanto professora mediadora, ela recebe encaminhamentos dos outros docentes, inclusive casos envolvendo a questão racial, segundo a professora de Português:

Porque ali na sala, por exemplo, quando eu vejo as meninas chamando o $M$. de macaco, eu fui lá falar com a $S$. (coordenadora pedagógica): "olha está acontecendo bullying lá, eu não estou conseguindo controlar, pelo amor de Deus". Ai a gente teve a intervenção da Natália, que conversou com eles e eles falaram para ela: "pode ficar tranquila que aqui tudo o que a gente faz é brincadeira". (Sofia)

Dessa forma, os alunos se aproveitam da fragilidade da docente para dar continuidade àquilo que eles chamam de brincadeira e que faria parte da cultura própria das crianças (Gomes, 2012). A docente não teria acesso à tal cultura e, por isso, teria dificuldade de manter uma conversa mais aprofundada sobre o tema. A existência dessa cultura é verificada também na fala de Mônica sobre o racismo:

... é uma questão muito velada, porque entre eles mesmo, existe esse código. Como, aliás, entre nós, brasileiros, existe essa tendência em não aceitar porque é uma coisa que se discute muito, porque é errado, porque isso, porque aquilo, mas a gente percebe sim, algumas coisas veladas... (Mônica)

O que seria tratado como "cultura das crianças" ou apenas "brincadeira" descredita a discriminação racial e reflete a forma como a sociedade brasileira tem identificado o racismo nas relações interpessoais, interpretando-o pela concepção individualista, conforme Almeida (2018), a qual minimiza e naturaliza as microviolências. A percepção de Mônica demonstra o lugar nebuloso e velado do racismo à brasileira, conforme concebeu Telles (2003), revelando como a discussão sobre o assunto ainda é incipiente. Parte dos professores e coordenadores apresenta dificuldades de entender teoricamente como isso é um espelho da própria sociedade brasileira e como a prática do não enfrentamento se torna uma propagação do racismo, caracterizada pela concepção institucional, segundo Almeida (2018).

Maraíde, professora de Português, expõe sua dificuldade em desconstruir o racismo. Ela propõe que todas as situações conflitivas acontecem por falta de conhecimento do posicionamento e da visão de mundo do outro. Nesse sentido, situações envolvendo as relações étnico-raciais devem ser solucionadas por meio de conversas entre as partes. A docente afirma que a atitude de discriminação racial dos alunos é fundamentada principalmente na experiência familiar, mas, "como aconteceu comigo", diz Maraíde, pode haver uma quebra na corrente das heranças familiares:

O que eu percebo, muitas vezes, há alguns adolescentes, eles vão muito de embalo, é aquela coisa assim, eu não gosto, sei lá, um exemplo assim, "Eu não gosto do negro", "Mas por que você não gosta?" "Ah, porque minha familia não gosta..." "Mas pera aí, por quê?" A pessoa não sabe. "Ah não, porque me ensinaram assim, ah..." Eu partiria para a questão do conhecimento, sentar com os envolvidos e dizer vamos conhecer. (Maraíde) 
Maraíde identifica o racismo presente na sociedade brasileira como sendo transmitido de geração em geração. Como profissional da educação, não surpreende que a categoria e o recurso mobilizados na situação sejam o "conhecimento". No entanto, não se trata de um conhecimento intelectual ou acadêmico, mas um conhecimento social e individual sobre o outro que garantiria uma abertura para o reconhecimento do outro diferente por meio da alteridade; porém, "combater o racismo não significa lutar contra indivíduos, mas se opor às práticas e ideologias” (Muller, 2018, p. 88). Efetivamente, a solução encontrada por Maraíde pode ser funcional durante as suas aulas, respondendo a uma necessidade concreta de neutralizar o tempo e o espaço da escola e cumprir com suas obrigações profissionais, mas não podemos identificar aí uma luta contra o racismo institucional ou estrutural.

A solução proposta para os casos envolvendo a questão racial na escola é no âmbito individual e somente quando acontece alguma situação conflitiva. As conversas indutivas com os alunos para que conheçam e aprendam uns com os outros segue uma lógica liberal em que as relações entre indivíduos são privilegiadas, não tocando assim no seio do problema do racismo brasileiro.

No que concerne mais especificamente ao racismo de marca e aos efeitos da miscigenação, dois professores (Mônica e Eduardo) mencionaram o fato de que grande parte dos agressores são negros, assim como as vítimas. Eduardo comenta: "o que é engraçado é que é um racismo entre negros, não só entre branco e negro, um chama 'oh, seu negão fedido', um chamando o outro, né” (Eduardo).

A fala desse docente nos permite ratificar a existência de uma não identificação por parte de alguns negros com sua cor, sua origem e sua cultura. Tal fenômeno tem sido construído histórica e culturalmente no Brasil, desde o regime escravocrata. $O$ professor Eduardo, assim como os alunos, não reconhece a seriedade desse tipo de comportamento relacional e trata os casos como naturais, pontuais e corriqueiros. Sua estratégia de ação é evitar uma discussão aprofundada sobre o tópico e procurar voltar a atenção dos alunos para a aula o mais rápido possível.

A hipótese de Mônica é que os alunos percebem uma diferença na cor da pele, o que seria o argumento para a discriminação racial. Em outras palavras, alguns alunos negros de pele mais clara, que não se reconhecem como tais, agridem seus colegas negros de pele mais escura. Assim, o tom da pele determina aqueles que terão maiores obstáculos sociais e sofrerão mais preconceitos. A docente explicita uma experiência que viveu e que lhe foi reveladora da posição geográfica marginal que ocupam os negros na sociedade brasileira. Mônica tinha acabado de mudar de escola, indo lecionar na periferia de São Paulo e, em sua sala, percebeu uma aluna que chorava:

... uma menina assim, bem negra, que é difícil a gente ver, né, bem negro, bem negro, o cabelo bem curto, e aí, ela não queria fazer nada, eu já percebi que tinha uns alunos rindo. Eu já tirei da sala para perguntar o que estava acontecendo, ela estava em choque, não queria falar, não queria me falar e ai eu chamei a direção, a direção levou para conversar, eu não conhecia muita gente na escola na época... . Ai uma aluna falou "professora, da hora que ela chegou, eles estão tirando sarro dela porque ela é preta". Parece que ela tinha vindo de Minas. "Porque ela é preta, porque o cabelo dela écurto, porque ela estava de chinelo de dedo, ela estava com uma sainha, não tem nada a ver com as roupas que as meninas usam aqui, com uma saia, uma camiseta..." (Mônica)

A professora descreve que ficou surpresa e "meio sem saber o que fazer, apesar da minha experiência”, disse ela. O fato de ser novata na escola conferia-lhe pouca autoridade para tocar em um assunto tão delicado. Por isso,

Preferifalar algo assim: "olha, gente, vamos respeitar, a aluna é nova, está num ambiente novo, já é difícil para ela e vocês ficarem tirando uma da cara dela...", mas não passou muito disso, inclusive por questões de horário, eu não consegui ficar nessa escola. Eu sai. Mas era uma escola que tinha essa questão sim, muito mais evidente. (Mônica)

Por mais que a estratégia de ação de Mônica tenha sido envolver os alunos em uma discussão, a necessidade de se proteger como docente recém-chegada na escola fez com que o seu discurso não 
correspondesse às questões fundamentais que integram a discriminação racial. Ou seja, mais uma vez, a oportunidade de trabalhar as questões raciais aparece em sala de aula, mas ela é distanciada pela docente, por mais que seja uma profissional que tenha uma sensibilidade pessoal e uma capacidade intelectual para fazê-lo. Essa atitude é justificada por ela pelo fato de ser novata na escola e não saber como seria a reação da direção e de suas colegas. Pouco tempo depois, Mônica deixou essa escola.

Esse fenômeno é compreendido por Silva (2018) como o silenciamento docente, que é constatado em diversas pesquisas (Pereira, 2011) que se debruçam sobre o racismo, o etnocentrismo e outras discriminações. A análise de artigos sobre esse tema de 2003 a 2014 permitiu que a autora afirmasse que a única medida tomada pela escola é incentivar os alunos a ignorar as agressões que sofrem, estimulando, assim, uma cultura do silenciamento ou, como diz Anderson, outro professor entrevistado, "da sociedade do fingir". Entende-se aqui que o silenciamento faz parte de um processo de construção social que torna a discriminação social invisível. Outros indícios serão apresentados a seguir.

\section{A Lei n. 10.639/2003}

O artigo 26 da LDB n. 9.394/1996 foi alterado pela Lei n. 10.639/2003, que normatiza a obrigatoriedade da inclusão da temática da cultura e história da comunidade afro-brasileira nos estabelecimentos de ensino fundamental e médio. Essa alteração é um instrumento de descolonização do currículo na concepção de Gomes, N. (2012). Isso significa um enfrentamento legal à ideologia historicamente propagada nos currículos, nos quais os negros são retratados de modo pejorativo, conforme discutido anteriormente. Em razão da obrigatoriedade, os professores pesquisados precisaram se confrontar com a temática e se posicionar frente à lei.

\section{"Não gosto, mas me obrigam"}

Sofia é professora contratada de Português e de Inglês há cinco anos na rede estadual e se autointitula "conteudista". Sofia se identifica como uma mulher negra e, ao falar de sua trajetória de vida, descreve diversos momentos em que sofreu discriminação social por conta da cor da sua pele. Contudo, descreve que as humilhações e as injustiças foram o que a impulsionaram a fazer escolhas e a chegar à posição ocupada (Dubet, 2014): sua profissão é vista como uma forma de ascensão social.

Sofia não se identifica com a cultura africana e não traz a questão da ancestralidade negra nas suas formas de ser, agir e pensar. Prefere seu cabelo liso e frequenta a Assembleia de Deus desde tenra idade. Outro indício de sua não identificação com a cultura negra está em sua fala. Ela utiliza o pronome "eles" para se referir aos negros, aqueles que "praticam" as africanidades; ou seja, existe um grupo de pessoas ligado às africanidades que é diferente do grupo de pertencimento da professora: "eles têm uma religião muito... a religião que sofre bastante preconceito e nessa religião a gente percebe [situações de discriminação racial]." Assim, por mais que Sofia tenha consciência dos elementos culturais e das consequências que seu fenótipo lhe traz, para ela, trabalhar com a história e a cultura africanas é apenas responder a uma demanda legal:

Eu estou trabalhando isso não porque eu gosto, eu estou trabalhando isso porque eu devo e está na legislação.... É minha obrigação, a legislação ela fala que eu tenho que trabalhar africanidades todos os anos... Agora no Português a legislação ela fala que você tem que inserir algum projeto de africanidade com o objetivo que o aluno venha tirar esse senso comum e tolerar as outras religiöes. (Sofia)

A injunção de trabalhar com africanidades no currículo é uma obrigação cumprida pela professora por meio de músicas, confecção de cartazes, capoeira e literatura (quando disponível). Seu principal objetivo na realização das atividades é transmitir o valor de respeito, mesmo que ela não se sinta à vontade para defender o direito à liberdade de crença ou as vítimas de discriminação religiosa. Respeitar sem defender é, mais uma vez, uma ação individual que não toca as estruturas do coletivo, uma vez que a atitude do respeito não possui uma função ativa para incluir e, portanto, não é entendida 
como um "fator que afeta todos e todas" (Coelho, 2018, p. 113). A exclusão, dessa forma, acaba reproduzindo o racismo estrutural brasileiro.

\section{Justificativas para o não cumprimento da lei}

Uma das características da profissão docente é a resistência às mudanças (Dubet, 2000), principalmente quando estas são impostas de cima para baixo, ou seja, de prescritores que não necessariamente conhecem a realidade escolar. A implementação da cultura e da história afro-brasileiras por meio da lei implica uma dupla resistência: a primeira delas relacionada à mudança em si e a segunda ligada ao fato de que se trata de uma mudança que propõe transformar valores sociais impregnados na sociedade brasileira pela valorização do que é desvalorizado.

A conquista do movimento negro em relação à aprovação da Lei n. 10.639/2003 traz para os docentes uma nova injunção profissional na forma de uma prescrição curricular. Como vimos no caso de Sofia, por vezes, a inovação curricular não agrada todos os professores e eles acabam utilizando estratégias para adaptar o cumprimento da norma legal (Valente, 2010; Lantheaume \& Hélou, 2008). Em outras palavras, o currículo real não corresponde tal qual ao currículo prescrito (Gimeno-Sacristán, 2000; Forquin, 1993). Além da resistência pessoal dos docentes em aceitar ou não as prescrições, outras dificuldades impedem a implementação da Lei n. 10.639/2003. Três docentes explicitaram alguns dos obstáculos encontrados no exercício da atividade docente.

A professora mediadora, Natália, afirma que a proposta de trabalhar com a história e a cultura africanas "não é aceita pelos professores ainda", por conta de uma série de preconceitos, entre eles o de falar do papel da cultura africana no Brasil colonial. Efetivamente, se, por um lado, a lei força a reconhecer que os negros foram os grandes motivadores para a povoação e enriquecimento do Brasil Colônia e o motor para a mudança social e política nesse período histórico (Moura, 1992), por outro, a estrutura social os coloca nas posições menos prestigiadas. $\mathrm{O}$ paradoxo parece ser muito grande para sua abordagem em sala de aula.

A resistência dos docentes é explicada por Natália por conta da ausência de formação. Contudo, essa justificativa está atrelada também ao fato de que os professores precisariam dispor de condições financeiras para tal, além de abrir mão de seu tempo livre.

A formação poderia ser uma resposta e uma motivação também para a ação da professora Maraíde. Para ela, o trabalho sobre a cultura e história afro-brasileiras não sai do papel, pois os professores são inseguros e têm dificuldades para argumentar e enfrentar questionamentos dos pais, alunos ou colegas:

Ai sempre gera aqueles conflitos e as discussóes internas né, e ai acaba ficando essa coisa meio fragmentada né, agora falando de Olimpiadas é bonito né, colocar os negros que fazem parte do esporte, faz o painel, né, fala, são os negros que fazem parte do esporte e acabou.... Eu acho que é um corte do próprio professor.

Pesquisadora: Por quê?

Maraide: É insegurança. Eu acredito que seja insegurança, é o não saber se colocar diante do assunto, de falar assim "Olha, eu não estou aqui para mudar a opinião de ninguém”, é até mesmo contraditório, falar que nós somos formadores de opinião, mas assim, eu tô aqui para apresentar que dentro dessa cultura existe tal religião que é discriminada por praticamente a maioria das pessoas que não gostam. Eu não tenho nada contra. Não tenho, já li, não tenho assim, mas assim, eu percebo isso, porque, quando chega nessa questão, "Ah vamos falar..." "Ah, não..." um pouco éo desconbecimento, essa questão de que se eu for cobrado por um pai por exemplo, como que eu vou argumentar. Para argumentar você precisa conhecer; então as pessoas fogem disso. (Maraíde) 
As resistências são outras para Carlos Alberto. O professor de História e vice-coordenador de uma escola da Zona Leste de São Paulo afirma que há uma objeção de trabalhar determinados temas na escola por parte não apenas dos professores, mas também dos alunos. Carlos Alberto nomeia o momento histórico de radicalidade pouco reflexiva que censuraria determinados assuntos de serem trabalhados nas escolas, sendo um deles a história e a cultura afro-brasileiras.

A ausência de formação ou a resistência de pais, alunos e colegas ou, ainda, a existência de valores incompatíveis com a mudança de perspectiva sobre as relações étnico-raciais no Brasil seriam apenas bodes expiatórios para o não cumprimento da lei. Ou seja, a estratégia de ação mais frequente dos docentes é a relativização mediante as situações relacionadas com a Lei n. 10.639/2003. Por relativização, entendemos que, nesse caso, os professores estão conscientes da dívida existente entre a prática docente real e a prescrição curricular, mas se satisfazem com ela (Lantheaume \& Hélou, 2008), pois dessa forma facilitam o próprio trabalho e evitam embates.

De forma geral, as situações são apresentadas pelos docentes como justificativas mais ou menos fundamentadas para o não cumprimento da Lei n. 10.639/2003. Conforme afirma Miranda (2012), no contexto de intolerâncias religiosas, a legalidade não possui reconhecimento suficiente para lidar com situações de discriminação na sociedade brasileira, até porque ela própria minimiza os casos. De qualquer forma, fica claro que a injunção legal não passa por um processo de transposição didática; ela requer um esforço de militância, de formação e de interesse pelo tema por parte dos professores. Motivação essa que não pode ser imposta, existindo apenas se partir do próprio professor. Por outro lado, a lei, junto às prescrições curriculares, respalda e legitima as práticas docentes dos professores que, usufruindo de sua autonomia docente, propõem atividades que permitam uma postura mais reflexiva e autônoma dos alunos, mesmo quando o docente não possui um apoio no espaço escolar.

\section{Racismo religioso}

A expressão racismo religioso foi criada pelo movimento negro e esteve presente no debate jurídico sobre cotas raciais, principalmente no ano de 2012. Esse termo é utilizado para designar situações em que o racismo é a base da discriminação contra religiões de matrizes africanas, sendo insuficiente o conceito de intolerância religiosa (Oliveira, 2017). O racismo religioso é mais uma forma de depreciação da cultura negra ou afro-brasileira por meio de sua dimensão religiosa e tem origem no período colonial e escravocrata. Essa forma de discriminação racial, que foi primeiramente praticada pelo catolicismo, tem ganhado força em outra vertente do cristianismo com a expansão das igrejas pentecostais e neopentecostais nos últimos anos. Com o aumento da militância negra, o debate sobre o respeito e a tolerância religiosa tem ganhado certo destaque em uma área que ficava na subalternidade religiosa. Destacamos a seguir duas situações que abordam a questão.

\section{Interpretações sobre a censura do jongo}

O professor de Educação Física da Escola Academia decidiu trabalhar com a dança do jongo. Embora o caso tenha sido descrito por três docentes (Gabriel, Marta e Sarah), nenhum dos entrevistados participou da situação ativamente. Ela aconteceu há alguns anos quando o professor de Educação Física preparava uma apresentação de jongo na festa tradicional da escola no mês de junho. O pai de um aluno escreveu uma carta de repúdio a essa prática, alegando que a dança teria elementos "de macumba".

Houve diversas trocas entre os professores para discutir como responder ao pai. Embora apenas uma professora tenha sido explicitamente solidária com a solicitação do pai, a decisão da direção escolar, naquele momento, foi de suspender a apresentação. Contudo, durante as entrevistas, os três professores lamentaram essa decisão e afirmaram que o jongo seria, atualmente, uma bandeira da escola, representando uma manifestação cultural periférica e negra que faz parte da diversidade cultural brasileira. 
Para Gabriel, professor de História, trata-se de um embate cultural entre o pai do aluno e a proposta docente. Enquanto o pai vê o jongo como uma manifestação religiosa, Gabriel e a equipe de professores percebem a dança de origem africana como uma manifestação cultural:

$A$ área de ciências humanas manifestou o apoio a esse professor, dizendo que entendia que o jongo estava sendo usado ali como uma manifestação cultural, não como proselitismo religioso, que não estava havendo culto a nenhuma divindade e tudo mais.... Era só o uso musical. Eu lembro que na época a gente teve essa discussão que manifestou esse apoio [ao professor de Educação Física]. (Gabriel)

Para a professora de Gramática, Marta, a decisão da escola parte de uma "frouxidão administrativa", que é paternalista frente aos alunos e à comunidade escolar, aceitando demandas parentais com base em uma lógica mercadológica: "a direção na época tomou um encaminhamento muito estranho, que desrespeitou essa convivência entre todas as religiões”. Segundo Marta, a decisão da escola fere não apenas o regulamento interno escolar, mas também o direito dos indivíduos como cidadãos.

A cultura do jongo como uma forma de transmissão da diversidade cultural brasileira não é um princípio individual desses professores, mas um dos princípios norteadores daquela instituição de ensino: "A Escola alargará a relação do sujeito com o objeto do conhecimento para além do conteúdo das disciplinas escolares tradicionais, incluindo as dimensões da produção cultural" (trecho do Projeto Pedagógico da escola).

É preciso lembrar que o jongo é uma dança popular originária da região africana Congo-Angola, importada pelos negros escravizados que foram trazidos para o Brasil, sendo praticada principalmente nas zonas rurais. Ou seja, embora faça parte da cultura, sua origem negra e mística torna o jongo uma prática periférica vítima de preconceitos, motivo pelo qual tal prática merece a defesa da docente. O amparo e o reconhecimento das escolhas pedagógicas e da prática docente se faz com o apoio do grupo de pares, fortalecendo a autonomia e a legitimação do profissional da educação que é vítima de críticas externas à escola. A ação coletiva, contudo, é constituída de formação que se dá em exercício ou, em outros termos, de uma socialização profissional docente e por meio de, nos termos de Mafra (2003), uma cultura escolar.

Eu acho que a escola tem que ter momentos de debates dessas questões entre os professores, que a gente entraria naquele pacote de formação dos professores.... Eu não acho que essas formações elas garantem mudanças de atitudes ou que os professores saibam o que falar e façam a coisa certa para as situações ocorrerem, mas acho que a formação ela aumenta as chances disso acontecer. Agora as formaçôes também, elas dependerão assim, quer dizer, tem uma história de vida do professor, tem uma trajetória de visão de mundo, leitura de quem ele é, dos valores que ele é; então essa história de vida ela entra naquele ambiente de formação e vai fazer com que o professor seja mais ou menos aderente ao que está sendo proposto lá. Mas talvez um professor pouco aderente é melhor ele ter $10 \%$ de aderência do que, em relação ao como ele chegou lá, já vai ser um ganho, por isso que eu não descarto esse investimento em formaçôes. (Gabriel)

Repertório, experiência e respeito são as categorias mais utilizadas pelos entrevistados para avaliar a situação do jongo. $\mathrm{O}$ fato de possuírem grande parte da experiência docente como profissionais dentro da mesma escola (entre 15 e 20 anos de casa) favorece um compartilhamento de categorias de pensamento e visões de mundo, a qual valoriza a autonomia docente, a troca formal e informal entre os profissionais e a diversidade cultural brasileira.

\section{Empoderamento do aluno negro}

No mesmo estabelecimento do caso anterior, a Escola Academia, existe um projeto chamado Negritude, que data de antes da lei de 2003 e é um projeto da escola e não de um único professor, como é comum encontrar nas instituições escolares (Pereira, 2011). Ele propõe encontros mensais e é oferecido para os alunos do ensino fundamental I até o ensino médio. Por meio desse projeto a escola busca dar conta da heterogeneidade dos alunos, empoderando os alunos negros em sua construção identitária e promovendo debates sobre a discriminação racial no Brasil. 
Contudo, mesmo com tais propriedades, ocorreu nessa escola uma outra situação de racismo religioso, descrita pelo professor Ricardo, que lecionava a disciplina de História. Uma aluna sofreu retaliações dos colegas por conta do uso de um turbante, visto como um símbolo de pertença religiosa. Nesse sentido, a dimensão religiosa se mistura com a dimensão racial, uma vez que a menina era negra. A atitude do professor frente a essa situação foi de buscar o "empoderamento da aluna", conforme suas próprias palavras, sobretudo utilizando o argumento de que ela não precisa se envergonhar ou esconder sua identidade. Justifica sua atitude da seguinte forma:

Da mesma forma que você precisa acolher, atender o agredido e tentar agir numa situação de empoderamento dessa pessoa que está sendo agredida. Então, eu acho que nesses casos, que são os casos menos emblemáticos, que eles aparecem menos, a nossa interferência acaba sendo muito mais nesse sentido, de você atender um grupo para que o grupo se perceba como agressor, como alguém que está agindo com uma violência, que está discriminando, que, na maioria das vezes, ele não percebe isso, ele não faz isso deliberadamente, ele não discrimina, porque ele tem consciência de que esteja discriminando, pelo menos na fase de educação básica, na maioria das vezes. E você prestar atendimento a quem está sendo agredido no sentido de procurar estabelecer nele autoestima, $o$ empoderamento e até criar nele alguns mecanismos de defesa pra tentar, pelo menos, não aceitar ser tratado dessa forma. (Ricardo)

A palavra "empoderamento" está sendo aqui tomada como um termo nativo do professor. Contudo, seu uso como categoria analítica tem diversas concepções consoante Perkins eZimmerman (1995), dentre elas, o processo comunitário que permite uma transformação interna que leva à saúde mental. Não é por acaso que o termo tem sido utilizado entre os militantes negros como um processo de empoderar o indivíduo pela autoaceitação e autovalorização da identidade negra (Berth, 2018).

Essa estratégia de ação, ou seja, a promoção e o estímulo para que o aluno aceite e defenda suas características identitárias, foi também utilizada em uma outra situação de xingamentos racistas entre alunos, descrita pela professora Ana, da Zona Leste de São Paulo. Os dois professores são docentes experientes que lecionam a disciplina de História. Nas duas situações, o empoderamento gera efeitos na construção identitária do aluno, indo além dos muros da escola e desconstruindo a ideia da existência de um espaço social que pode e deve ser ocupado por determinadas pessoas, e combatendo assim o racismo institucional e estrutural. Contudo, os professores que relataram esse tipo de estratégia de ação frente a situações envolvendo a questão racial possuem uma reflexão, um envolvimento pessoal ou uma militância a favor da estrutura social, mas, sobretudo, eles não estão sozinhos. O compartilhamento de "valores inquestionáveis" (Marta) para um grupo de professores provoca uma certa homogeneização axiológica que é protegida, reafirmada e reproduzida nas e pelas ações docentes.

Identificou-se, assim, nesta pesquisa, que, para se embarcar na defesa dos sujeitos racialmente discriminados, os docentes que têm o apoio de seus pares têm a coragem, a motivação e o poder de agir contra a discriminação racial no espaço escolar.

\section{Considerações finais}

O corpus dessa pesquisa nos revelou que a maioria dos professores não coloca a discriminação racial como prioridade em sua prática docente. Os que a priorizavam faziam parte da Escola Academia, com exceção de uma professora. A escola em questão é diferenciada em diversos aspectos e as discussões com os alunos se dão não apenas no dia a dia da escola, mas também na forma de um projeto ampliado dirigido por vários professores e envolvendo um grande número de alunos. O diferencial é, com efeito, o empoderamento dos alunos por um lado e a formação e conscientização dos professores, por outro lado, sobre a importância da discussão racial. O fato de a escola adotar um projeto sobre negritude proporciona uma formação continuada sobre a temática das relações étnico-raciais que resulta em 
enfrentamentos do racismo nesse estabelecimento como parte da cultura escolar. Dito de outra forma, boas condições de trabalho favorecem a troca entre os docentes, a qual, por sua vez, alimenta a reflexividade e proporciona espaço para a criação de recursos profissionais que sejam capazes de interferir na transformação social, nesse caso, no combate antirracista.

Em contrapartida, a maioria das situações envolvendo as relações étnico-raciais narradas por docentes de outras escolas foi interpretada pelos professores como um jogo entre alunos, no qual os docentes não tinham ferramentas ou não se sentiam competentes para intervir. Mesmo quando os docentes propõem soluções para os conflitos, elas ocorrem no âmbito individual e pontual e não têm potencialidade para o questionamento social sobre o racismo estrutural e institucional vivido no Brasil. Em outras palavras, o racismo se reduz à concepção individualista.

Tal naturalização da discriminação e a presença da "cultura racista" no centro da escola reproduzem as desigualdades sociais, pelo racismo institucional, e são as provas de um acesso ainda difícil à educação de direitos para a cidadania. A dificuldade do corpo docente em lidar com o tema do racismo sugere que a educação para a igualdade precisa, primeiramente, ser destinada aos profissionais da educação. O desconhecimento das concepções do racismo - individual, institucional e estrutural; de marca ou de origem - da sociedade brasileira não lhes permite enfrentar as práticas racistas que permeiam as relações sociais no ambiente escolar. Assim, a relativização e a invisibilização da questão da discriminação racial por parte dos professores são mecanismos que fazem parte de um processo social que reflete o racismo estrutural na sociedade brasileira. Não queremos com isso culpabilizar os docentes, mas revelar o fato de que eles não possuem consciência sobre a influência de suas crenças em suas práticas profissionais (Gay, 2014).

Apesar de a Lei n. 10.639/2003 ser uma conquista do movimento social negro e representar um passo em direção à mudança da estrutura social, Muller (2018) revela transformações pouco significativas e impactantes nos livros didáticos. Essa pesquisa, por sua vez, mostra que a lei é pouco aplicada no currículo real pelo fato de não ser acompanhada por políticas públicas de formação. A fragilidade no percurso formativo é identificada por Coelho (2018) como tema recorrente em artigos, teses e dissertações publicados entre 2003 e 2014 sobre a formação de professores e as relações étnico-raciais. Além da possibilidade de crítica desse instrumento legal com base na formação docente, inspirando-se em Glass (2012), afirma-se que a lei propõe uma espécie de sensibilidade racial focada na história e na política das relações sociais, abordando a raça pela questão da multiculturalidade, mas sem revelar a diversidade de identidades raciais existentes e sem apontar as relações de poder que transformam as diferenças em desigualdades. Dessa forma, a Lei n. 10.639/2003 seria um primeiro passo para a crítica racial no espaço escolar, crítica social essa cuja criação e implementação precisam ser conhecidas e discutidas pelos docentes a fim de contribuir para o combate ao racismo estrutural brasileiro.

Para Glass (2012, p. 898), “a identidade racial não é um princípio básico conhecido”, ou seja, ela deve ser construída de acordo com a configuração sociocultural na qual o indivíduo vive. A escola fornece experiências escolares que não pertencem aos indivíduos, pois são exteriores a eles, mas elas permitem que os atores passem por um processo de autoconstrução de suas identidades (Dubet \& Martuccelli, 1996). Nesse sentido, uma intervenção docente que permita que os alunos reconheçam as contradições e as diversidades (ligadas ao gênero, à classe social, às diferentes etnias) como identidades cultural e historicamente construídas possibilitaria também a desconstrução de pressupostos quando se propõe a reflexão sobre a política de poder existente nas relações sociais, assumindo-se a responsabilidade pela transformação social para si e para o coletivo. Necessita-se, pois, de uma formação docente mais qualificada para que a conquista legal se efetive no currículo real. Contudo, sua efetividade dependerá de condições de trabalho que favoreçam a discussão sobre as relações étnico-raciais e sobre a função social da escola na luta antirracista. 


\section{Referências}

Albuquerque, E. (2009). Avaliação da técnica de amostragem "Respondent-driven Sampling" na estimação de prevalências de doenças transmissiveis em populaçōes organizadas em redes complexas [Dissertação de Mestrado]. Escola Nacional de Saúde Pública Sérgio Arouca, Fiocruz; Ministério da Saúde, Rio de Janeiro.

Almeida, S. L. (2018). O que é racismo estrutural? (Coleção Feminismos Plurais). Letramento.

Amigues, R. (2003). Pour une approche ergonomique de l'activité enseignante. Skholê, hors-série, 1, 5-16.

Beaud, S., \& Weber, F. (2014). Guia para a pesquisa de campo: Produzir e analisar dados etnográficos. Vozes.

Berth, J. (2018). O que é empoderamento? Letramento.

Blais, M., \& Martineau, S. (2006). L'analyse inductive générale: Description d'une démarche visant à donner un sens à des données brutes. Recherches Qualitatives, 26(2), 1-18.

Boltanski, L., \& Thévenot, L. (1991). De la justification: Les économies de la grandeur. Gallimard.

Clot, Y. (2008). Travail et pouvoir d'agir. PUF.

Coelho, W. N. (2018). Formação de professores e relações étnico-raciais (2003-2014): Produção em teses, dissertações e artigos. Educar em Revista, 34(69), 97-122.

Cunha, L. A. (2017). A educação brasileira na primeira onda laica: Do Império à República. Edição do Autor.

Darmon, M. (2016). La socialisation. Armand Colin.

Dubet, F. (2000). Peut-on encore reformer l'école ? In A. Van Zanten (Dir.), L'école: L'état des savoirs (Textes à l'appui, série l'état des savoirs). Éditions la Découverte.

Dubet, F. (2014). Injustiças: A experiência das desigualdades no trabalho. Editora UFSC.

Dubet, F., \& Martuccelli, D. (1996). À l'école: Sociologie de l'expérience scolaire. Le Seuil.

Forquin, J-C. (1993). Escola e cultura: As bases sociais e epistemológicas do conhecimento escolar. Artes Médicas.

Freyre, G. (2004). Casa-grande \& senzala: Formação da familia brasileira sob o regime da economia patriarcal (49a. ed.). Global. (Primeira edição publicada em 1933)

Gay, G. (2014). Atuando nas crenças na formação de professores para a diversidade cultural. Educação em Foco, $17(24), 93-121$.

Gimeno-Sacristán, J. (2000). O currículo: Uma reflexão sobre a prática. Artmed.

Glass, R. (2012). Entendendo raça e racismo: Por uma educação racialmente crítica e antirracista. Revista Brasileira de Estudos Pedagógicos, 93(235), 883-913.

Gomes, L. (2012). Particularidades da infância na complexidade social: Um estudo sociológico acerca das configurações infantis [Tese de Doutorado]. Faculdade de Educação, Universidade de São Paulo, São Paulo.

Gomes, N. (2012). Relações étnico-raciais, educação e descolonização dos currículos. Currículo sem Fronteiras, 12(1), 98-109.

Gomes, N. (2017). O movimento negro educador: Saberes construidos nas lutas por emancipação. Vozes.

Gomes, N., \& Jesus, R. (2013). As práticas pedagógicas de trabalho com relações étnico-raciais na escola na perspectiva de Lei 10.639/2003: Desafios para a política educacional e indagações para a pesquisa. Educar em Revista, (47), 19-33.

Guimarães, A. S. (2009). Racismo e antirracismo no Brasil (3a. ed.). Editora 34.

Haidar, M. L. (2008). O ensino secundário no Brasil Império (2a. ed.). Edusp.

Hasenbalg, C. (2005). Discriminação e desigualdades raciais no Brasil (2a. ed.). Editora UFMG; IUPERJ.

Hasenbalg, C., \& Silva, N. (1999). Educação e diferenças raciais na mobilidade ocupacional do Brasil. In C. Hasenbalg, N. Silva, \& M. Lima. Cor e estratificação social. Contra Capa Livraria.

Jones, J. (1973). Racismo e preconceito. Edusp.

Lantheaume, F., \& Hélou, C. (2008). La souffrance des enseignants: Une sociologie pragmatique du travail enseignant. PUF.

Lein. 10.639 de 9 de janeiro de 2003. (2003). Inclui no currículo oficial da Rede de Ensino a obrigatoriedade da temática "História e Cultura Afro-Brasileira". Ministério da Educação, Brasil.

Lima, M., \& Prates, I. (2015). Desigualdades raciais no Brasil: Um desafio persistente. In M. Arretche (Org.), Trajetórias das desigualdades: Como o Brasil mudou nos últimos cinquenta anos. Editora Unesp; CEM.

Mafra, L. (2003). A sociologia dos estabelecimentos escolares. In N. Zago, M. P. Carvalho, \& R. A. T. Vilela (Orgs.), Itinerários de pesquisa: Perspectivas qualitativas em sociologia da educação. DP\&A. 
Menezes, N., Filho, \& Kirschbaum, C. (2015). Educação e desigualdades no Brasil. In M. Arretche (Org.), Trajetórias das desigualdades: Como o Brasil mudou nos últimos cinquenta anos. Editora Unesp; CEM.

Miranda, A.P. (2012). A força de uma expressão: Intolerância religiosa, conflitos e demandas por reconhecimento de direitos no Rio de Janeiro. [As máscaras de guerra da intolerância]. Comunicações do ISER, (66), 60-73. https://www.iser.org.br/publicacao/comunicacoes/66/

Moura, C. (1992). História do negro brasileiro. Ática.

Muller, T. M. (2018). Livro didático, educação e relações étnico-raciais: O estado da arte. Educar em Revista, 34(69), 77-95.

Munanga, K. (Org.) (2005). Superando o racismo na escola (2a. ed. rev.). Ministério da Educação, Secretaria de Educação Continuada, Alfabetização e Diversidade.

Nachi, M. (2012). Introduction à la sociologie pragmatique. Armand Colin.

Nascimento, A. (2016). Trabalhadores negros e o "paradigma da ausência": Contribuições à história social do trabalho no Brasil. Estudos Históricos, 29(59), 607-626.

Nogueira, O. (2006) Preconceito racial de marca e preconceito racial de origem: Sugestão de um quadro de referência para a interpretação do material sobre relações raciais no Brasil. Tempo Social: Revista de Sociologia da USP, 19(1), 287-308.

Oliveira, A. (2017). Religiões afro-brasileiras e o racismo: Contribuição para a categorização do racismo religioso [Dissertação de Mestrado em Direitos Humanos e Cidadania]. Universidade de Brasília, Brasília.

Perkins, D. D., \& Zimmerman, M. A. (1995). Empowerment theory, research, and application. American Journal of Community Psychology, 23, 569-579.

Pereira, J. S. (2011). Diálogos sobre o exercício da docência: Recepção das leis 10.639/03 e 11.645/08. Educação e Realidade, 36(1), 147-172.

Setton, M. (2012). Socialização e cultura: Ensaios teóricos. Annablume.

Silva, A.-C. (2005). A desconstrução da discriminação no livro didático. In K. Munanga (Org.), Superando o racismo na escola (2a. ed. rev., pp. 21-38). Ministério da Educação, Secretaria de Educação Continuada, Alfabetização e Diversidade.

Silva, P. B. (2018). Educação das relações étnico-raciais nas instituições escolares. Educar em Revista, 34(69), 123-150.

Telles, E. (2003). Racismo à brasileira: Uma nova perspectiva sociológica. Relume-Dumará; Fundação Ford.

Valente, G. A. (2010). Diferentes propostas curriculares para o ensino religioso e suas consequências para a laicidade do Estado [Trabalho Complementar de Curso/Graduação em Pedagogia]. Universidade de São Paulo, Faculdade de Educação, São Paulo.

Van der Maren, J.-M. (1995). Méthodes de recherche pour l'éducation. De Boeck Université; PUM.

\section{Nota sobre autoria}

Gabriela Valente foi responsável pela pesquisa empírica, portanto pela coleta de dados. Adriana S. R. Dantas contribuiu com a análise sobre as relações étnico-raciais dos dados coletados. O texto foi escrito em conjunto.

\section{Disponibilidade de dados}

Os dados desta pesquisa estão disponíveis em: https://data.scielo.org/dataverse/brcp

Como citar este artigo

Valente, G., \& Dantas, A. S. R. (2021). Práticas docentes e relações étnico-raciais: Reflexos da sociedade brasileira. Cadernos de Pesquisa, 51, Artigo e07327. https://doi.org/10.1590/198053147327 